as a sort of crisis capable of inducing the appearance of these symptoms." I have not so far been able to find this reference for myself, but the appearance or re-appearance of symptoms at pubarty have been recognised and catarrhal affections of the genital and other mucous tracts noted. With respect to the same in the adult, the objections to which such cases are liable are obvious, especially as regards genital mucous affections ; and yet amongst the numerous cases originally recorded ${ }^{3}$ of leucorrhoeas, uterine erosions, menorrhagia; in young unmarried women under the heading of "struma," it is almost impossible to doubt that some were unrecognised cases of inherited syphilis; more especially as under the "scrofulous diathesis affections of the eyes leaving interstitial deposition between the layers of the cornea" were noted. ${ }^{4}$

The subsequent histories in these cases are aggravation of symptoms on marriage with sterility ; or on cunception, mucoparalent or puralent discbarge through pregnancy, repeated abortions, or premature births, and subsequent pronounced uterine inflammatory disease. With regard to offspring there is but little noted in these treatises especially devoted to the diseases of women and there is only the note of offspring who either did not survive long or were healthy and the expression of belief in transmission of syphilis to the third and fourth generation in obvious form, or, amongst other causes, in the inherited syphilitic origin of "struma." Attention, however, appears to have been directed to the state of the husband in cases simulating acquired venereal disease, and in some of these cases he was as far as possible exculpated from blame. In some suspected cases of this group which have come under my own limited observation, well-marked notched central upper incisors have been present in the woman, or these teeth hare been entirely absent (Dr. Laycock, quoted by Dr. J. G. Beaney, stated that the characteristic groove is "usually obliterated by the twentieth year"); in other cases disease in the parent of the woman has been volunteered, and in a few cases I do not think there has been any reason to suspect the husband of past or present syphilis or gonorrhcea.

Whitehead recorded a possible case of general, genital and uterine manifestations in a young married woman. ${ }^{5}$

In this case he on inquiry traced a succession of symptoms from infancy, through childhood to adult age, marriage, and possible concep-

tion, and regarded them as due to syphilitic inberitance. His with the of syphilitic taint being raised he asked for an interview and acknowledged to disease in herself and secoud husband previously to the birth of the daughter.

At what time, however, the grandmother became contaminated by a first or second husband is open to doubt. Less objection can, perhaps, be taken to a case of Gilbert's quoted by Diday in farour of tardy inherited syphilis in the adult woman under the disturbing influence of conception:-

It is that of a young roman of bas constitution, who, after the birth of one infant who wasted rapidly and died on the seventeenth day, and of another healthy at the age of two, herself exhibited swellings, one of which, over the clavicle, suppurated and ulcerated. A nore also was noted on the tibia In this case there was reported syphilis in the parents of the woman, but no evidence or history of syphilis in the parents of the woman.

This group of possible cases, I admit, favours symptoms in the mother with abortions and premature births rather than actual transmission to the third generation. The possible case, however, adduced by Mr. (afterwards Sir John) Simon, and referred to by Mr. Nunn bears more directly.

The woman, whose father had died of tertiary syphilis, herself had a first child who was judged to be syphilitic, and had in her own person some symptoms which were ascribed to the same poison, there being not the smallest possibility of syphilis as far as could be ascer-
tained coming to her in any way otherwise than that of descent. 6

After previously acquired disease in the woman it is known that manifestations may re-appear in subsequent pregnancies in the form of syphilides, genital and uterine lesions, purulent discharge, abortions, premature births, full or partial transmission to offepring, with subsequent fever and confirmed inflammatory uterine and pelvic disease in the mother (or death of the mother in childbed, as noted from septicamia in one of Dr. Kolipinski's cases in THE LANCET of Dec. 9th). "Facts of this kind are numerous, and to be convinced of this it is only necessary to read the observations

3 J. Whitehead, 1347-51; W. Tyler Smith, 1855; J. H. Bennett, 1861. 4 J. Whitehead: Abortion and Sterilitv, p. 61. 5 Hereditary Disenges, pp. 149,208 .

Discussion on Syphilis at the Pathological Scciety of London, 1876. furnished by authors." 7 Moreover, cases have been noted of syphilis in the offspring of women previously diseased by a first and married to a second, even third, healthy husband, the woman herself apparently remaining healthy or exhibiting only uterine disease.

From such facts as these it is difficult to believe that the same disturbance of latency and transmission to offspring may not occur in the case of inherited syphilis; that if symptoms are present in the mother they may not be due to revival of disease in herself rather than re-infection; and that there is no survival of hereditary taint in some at least of her offspring. The same argument, of course, applies to cases in which the woman has acquired disease previously to marriage. The question also of acquisition in infancy cannot be ignored, with subsequent symptoms in adult life. In Whitehead's case previously referred to, and possibly in Diday's, Simon's, and in unsuspected others, there may have been acquired syphilis in infancy or childhood, with re-appearance in the innocent woman of manifestations on conception, or maternal transmission. Whitehead records a definite case of lip infection in a girl of 11 years of age with subsequent constant leucorrhœe, vaginal irritation, and other symptoms, who ten years later gave birth to a syphilitic infant followed in the mother by uterine inflam. matory disease, while the husband in this case had "never suffered from syphilis in any shape." 9

I am, Sirs, yours faithfully, JohN A. SHAW-MaCkENZIE.

Grosvenor-street, W., Jan. 22nd, $19 \mathrm{CO}$.

\section{"THE UNIVERSITY OF LONDON ELECTION : THE CANDIDATURE OF DR. W. J. COLLINS."}

To the Editors of THE LANCET.

SIRS,-The anonymous letter which appeared in THE LANCET of Jan. 13th under the above heading contains at least one mis-statement of fact, but it breathes such a tone of virulent opposition as to render a reply hardly necessary. I rely, however, on your well-known love of fair play to permit me to add a word or two to the comments contained in your arnotation on the same subject in which you say (p. 117) that Dr. Collins is "at variance with accepted scientific belief on the question of vaccination." As one of the Royal Commissioners appointed by Her Majesty to inquire into the subject of vaccination Dr. Collins has had exceptional opportunities for studying the subject and has given us his views at considerable length in what is known as the "Dissentients' Report," signed by Mr. Picton and himself. It would occupy too much space to quote from this at sufficient length, but I cannot do better than refer to the leading article in THE LANCET of Oct. 31st, 1896, p. 1241. In dealing with that report you adopt the following as a summary of the views held by these gentlemen:-

One thing is certain from a perusal of the very guarded terms in which the dissentient Commissioners refer to vaccination, and that is that they believe vaccination to be a means of protection against small-pox. Nowhere, as we point out in another column, do they express a disbelief in vaccination as a power against small-pox. Inreed, they go far beyond giving this negative testimony of their faith in vaccination. They assert in a positive form that it is both an "effective and trustworthy prophylactic" because they propound the question in a comparative form as to whether vaccination can be regarded as a "more" effective and trustworthy agent in the control of small-pox than sanitation and isolation. Then, again, they really advocate vaccination, for they actually suggeat that "moral influence" may properly be used in pressing it upon the population, and this attitude pretty well disposes of their having any belief in the terrible
risks which, according to some people, are involved in the operation. risks Which, according to some people, are involved in the operation.
With some of the recommendations of the dissentients it is obvious With some of the recomm

It is possible that Dr. Collins may not be "an embodied expression of the highest medical opinion," though I personally should not be inclined to admit even this without discussion, in view of his vast knowledge of this and other subjects, and the distinguished position he has taken at our university examinations. But I de not think anyone after a careful perusal of the report in question and the valuable criticism of THE LANCET thereon can maintain that Dr. Collins is at variance on any important or vital point with the accepted scientific belief on the question of vaccination. Indeed, he has won the cordial support of hundreds of his

$\tau$ E. Lancereaux : A Treatise on Syphilis, vol. ii., p. 265.

8 J. Whitehead, p. 118. On Venereal Disease, A. Vidal (de Cassis), p. 459 . Constitutional Syphilis, J. G. Beaney (1880), p. 350 . 
fellow graduates, including a large number of medical and surgical alumni of the University of London, who believe he wculd be as useful in Parliament as he has been in the London County Council.

I am, Sirs, yours faithfully,

Thomas D. SavilL.

Upper Berkeley-street, W., Jan. 16th, 1900.

\section{PROPOSED PUBLIC MEDICAL SERVICE.}

\section{To the Editors of THE LANCET.}

SIRs,-I am glad to see that Mr. M. J. Houghton is develop ing the above proposal. In the British Medical Journal of June 22nd, 1889, I suggested the formation of such a service. At first I suggested that it should contain only one department which I termed the "cash fee department." But Dr. H. Woods pointed out to me that it should contain also a department by which persons in health could insure for treatment when ill. I agreed to recommend a provident department also. I think two or three such public medical services exist-one in Coventry and one in Hartlepool. They have not, I understand, adhered to all my suggested rules. At present I would not advise that this name be continued and $I$ would suggest that in place of it the term " Provident Medical Service" be adopted.

My aim in suggesting such a service was to show that, from long back, practitioners should not have left it to non-medical persons to establish sick-clubs of any kind whatsoever. I took up this position-that the wage-paid classes have no more right to employ me as their medical servant in a sick-club capacity than $I$ have to interfere with (or exploit) the grocer, \&c., who kindly sells to me groceries, \&c. Let all practitioners agree not to act as medical officers to all sick-clubs; let the sick-clubs carry on their chief functions as related to sick pay, funeral allowance, \&c. ; let a provident medical association be established in each town, with branches if necessary, and then touting for clubs, the medical aid association nuisance, hospital abuse, and kindred subjects will disappear. The question of hospital abuse can never become a practical question until such a service is in thorough working order, as it would be cruelty for a hospital committee to refuse treatment unless they could refer the applicant to such a trusted service. My only fear is that such a service would run a great danger of being ruined by not having a rigid " wage limit" for membership, and thus hospital abuse if corrected at the hospital would not be cured but only transferred to the service. Doctors are a most unbusinesslike class.

Liverpool.

I am, Sirs, yours faithfully,

ROBERT R. RENTOUL.

\section{MOSQUITOS AND MALARIA. \\ To the Editors of THE LANET.}

SIRs,-Permit me to call attention to a slight error that is expressed in your columns ${ }^{1}$ in regard to the discovery of the anopheles as a carrier or host of the quartan malarial parasite. It is stated that "within a short time of his arrival at Sierra Leone Major Ross was able to telegraph that he had found the malarial organisms within the bodies of the anopheles and further that he had proved that the insects would also act as carriers of the quartan parasite." As Grassi, Bignami, and Bastianelli ${ }^{2}$ published on Feb. 5th, 1899, that they had succeeded in experimentally infecting anopheles claviger with quartan parasites by feeding it on a woman suffering from a severe quartan infection and that they had found stages of development of the organism in the stomach wall of the mosquito so infected, it is clear that the credit of the discovery is due to them and not to Ross. I have been influenced to call attention to this fact for the reason that on several previous occasions the same error has found expression in the columns of THE LANCET and of other medical journals.

$$
\text { I am, Sirs, yours faithfully, }
$$

IRVING P. LxoN.

Buffalo, N.Y., U.S.A., Jan. 14th, 1900.

*** The claim which Dr. Lyon contradicts does not seem to us to be made in the words which he quotes.-ED. L.

1 The LanceT, Dec. 30th, 1899, p. 1819.

2 Reale Accademia dei Lincei, vol. viii., 5 febbraio, 1899.

\section{“THE MURMURS OF MITRAL STENOSIS."}

\section{To the Editors of THE LANCET.}

SIRS,-Dr. Sansom in your issue of Jan. 20th (p. 195) has protested against the statement in my letter of a fortnight previously that his article in Professor Allbutt's "System of Medicine" misrepresents me. I did not mean that his résumé of my views was inaccurate, but rather that it was calculated to leave an inaccurate impression. Dr. Sansom's quotations from my Paris thesis of 1896 show that I am largely responsible for this, since auricular hypertrophy, on which I there lay so much stress, implies an extra ("abnormal") powerful contraction of the auricle. In the thesis I magnitied the importance of hypertrophy as the most tangible part of the evidence of the possibilities of the auricle. This was out of consideration for the probable training and prejudices of the examiners for whom it was prepared. I imagined that if I could get them to admit the probability of my theory when the auricle was hypertrophied I might then lead them a step furtherviz., to recognise that it was also possible, at least theoretically, when the auricle was not hypertrophied. The thesis was well received as I gained a "très bien" for it and was asked to write a résumé for the "Archives de Médecine Expérimentale et d'Anatomie Pathologique," which I did.

A few pages beyond Dr. Sansom's second quotation from my thesis-viz., on page $41-I$ venture to state why I gave such prominence to the element of hypertrophy: "Pour satisfaire ceux qui croient plus à la force musculaire qu'aux principes mécaniques, j'attire encore une fois leur attention sur ce fait que j'ai toujours supposé une oreillette hypertrophiée et non dilatée." But I continued, p. 42: “Mais, même s'il n'y avait pas d'hypertrophie de l'oreillette (et je ne suppose pas que l'hypertrophie existe pour lui donner la faculté de résister au ventricule, ce à quoi il a été, j'imagine, toujours plus ou moins habitué, main pour lui donner le pouvoir de pousser le sang avec une vitesse suffisante au travers d'un orifice rétréci), il serait mécaniquement vrai qu'un ventricule vigoureux, lorsqu'il est gros, ne peut pas dilater une oreillette faible quand elle est suffisament petite, pas plus qu'un gros ballon. distendu, fait en caoutchouc épais, ne peut dilater un petit ballon, distendu, et fait en caoutchouc mince, lorsqu'il est mis en communication avec ce dernier." It is clear, therefore, that even in my Paris thesis, my earliest publication on the subject, I did not regard a hypertrophy of the auricle as essential though I have always maintained it to be helpful ; still that thesis, written against time as it was, has given undue importance to the valuable element of hypertrophy and justified Dr. Sansom's term "abnormally powerful" far more than my somewhat offensive expression " misrepresents me," which I very much regret having employed, and trust Dr. Sansom will add another to my many debts of gratitude to him by accepting my sincere apology.

The term "abnormal" evidently conveys a different impression to different minds. Thus in answer to my question "Is it abnormal that the smaller piston of a Bramah press should be able to force up the larger?" Dr. Brockbank replies "yes," where I should have said "no." His words are: "Yes, it is impossible for the smaller piston to press up the larger unless it be plunged with sufficient force to overcome the resistance of the large piston." Surely that is a normal and not an abnormal physical fact-a fact in hydrostatics which indicates that given suitable mechanical conditions a very weak force can overcome a very great resistance. Such a mechanical advantage the auricle has when it has nearly emptied itself and presents a small interval area to oppose a full ventricle beginning to contract and presenting a large internal area, for this is their relative condition as regards area when their contractions overlap.

Dr. Brockbank cannot get away from the idea of a considerable force to produce considerable pressure. If he will get a multiplying pulley gear and put a small child to pull the rope while he holds the free pulley, he will discover that the child can easily pull him over, but be must not conclude therefrom that the child exerts a man's force. Similarly if he experiment with a Bramah press, or the rubber balloons $I$ have more than once referred 